\title{
Wind Resistant Analysis of 5000m Hyperbolic Parabolic Spatial Mixed Cable Suspension Bridge
}

\author{
ZhaoYang Chen ${ }^{1 *}$ and WenPing $\mathrm{Xu}^{2}$ \\ ${ }^{1}$ CSCEC AECOM CONSULTANTS CO., LTD, Lanzhou China,730000 \\ ${ }^{2}$ College of Civil Engineering, Southeast University, Nanjing China,210096
}

\begin{abstract}
Combined with the engineering background of a 5000-meter Strait Suspension Bridge, the configuration study of the hyperbolic parabolic space cable suspension bridge was carried out, and the ANSYS finite element analysis model was established to analyze and study the structural internal force and dynamic modal characteristics. The research shows that the hyperbolic parabolic space mixed cable suspension bridge has excellent spatial stiffness and wind stability performance, its torsional frequency and torsional frequency ratio are significantly improved, the critical wind speed of flutter is greatly improved. In order to further improve the wind stability of the hyperbolic parabolic space mixed cable suspension bridge, temporary wind resistance cable measures adopted during strong typhoons are proposed. This method can ensure that the 5000-meter-level hyperbolic parabolic space mixed cable suspension bridge has the ability to withstand 120 $\mathrm{m} / \mathrm{s}$ rare extreme typhoons.
\end{abstract}

\section{Introduction}

As the span of the suspension bridge continues to increase, the structure tends to be softer, and its torsional frequency and torsion-bending ratio continue to decrease ${ }^{[1-2]}$. The key to the design is to check the stability against wind flutter under test wind speed ${ }^{[3-4]}$.

The structural rigidity of the super-span suspension bridge mainly comes from the main cable ${ }^{[5-6]}$. Therefore, the key point to improve the overall rigidity of the suspension bridge structure should be placed on the main cable. The use of a three-dimensional spatial cable suspension bridge structure system can effectively improve the wind-resistant stability of super-span suspension bridges ${ }^{[7-8]}$.

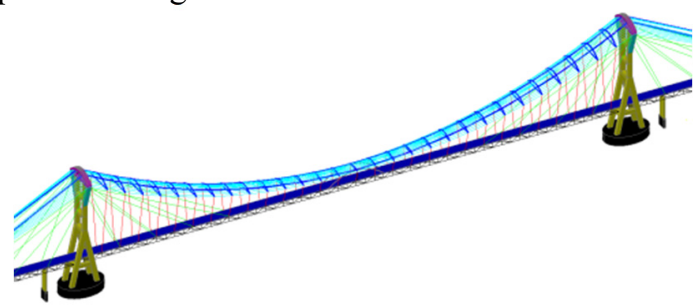

Figure 1. Super-long-span hyperbolic parabolic mixed spacial cable suspension bridge

In this paper, in conjunction with a 5,000-meter superlong-span suspension bridge, the configuration study of the super-long-span suspension bridge of the hyperbolic parabolic mixed space cable system was carried out. The ANSYS finite element analysis model was established to study the dynamic modal characteristics of the hyperbolic parabolic mixed space cable suspension bridge, and explore the advantages of the wind-resistant stability of the hyperbolic parabolic mixed space cable suspension bridge. This paper provides a theoretical basis for the construction of the super-long-span suspension bridge in the future.

\section{Design Parameters}

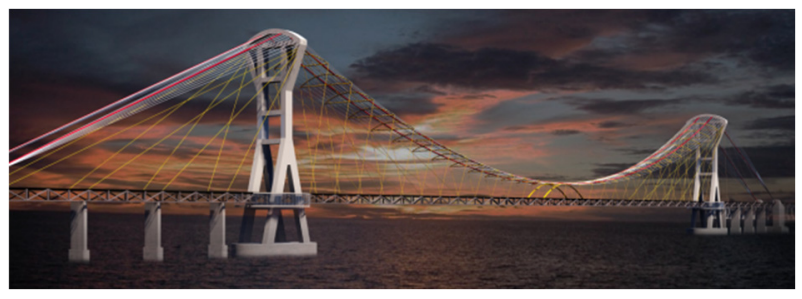

Figure 2. effect drawing of $5000 \mathrm{~m}$ hyperbolic parabolic spatial mixed cable suspension bridge

The super-span suspension bridge has a main span of 5000 meters, and adopts a single-span suspension bridge structure. The distance from the anchor to the tower is 1000 meters and the width of the deck is 60 meters. In order to meet the wind stability requirements of superlong-span suspension bridges, a new structural system of super-long-span suspension bridges with hyperbolic parabolic mixed space cable system was adopted.

The parallel steel wire rope adopts the prefabricated parallel wire strand method (PPWS method). The total length of the bridge is $5000 \mathrm{~m}$, and the vector span ratio is $1 / 11$. The parallel steel wire rope sags 454.5 meters. The

*ZhaoYang Chen: 807105720@qq.com 
parallel cable adopts the product of $\varphi 5.2 \mathrm{~mm}$ high-strength steel wire cable of $2000 \mathrm{MPa}$. A total of six steel cables are arranged on the whole bridge, and three cables are bundled together using a triangular method. Each main cable has a diameter of 1.6 meters.

The hyperbolic parabolic cable network adopts 4000MPa high-strength carbon fiber cables. The bridge has a total of 18 carbon fiber hyperbolic parabolic space cables with a diameter of 0.4 meters per main cable.

The curved steel beam with lower prestressed tension rods are set on the hyperbolic parabolic cable network and two parallel steel wire cables. The curved steel beam with a spacing of 120 meters and a cross-sectional size of $0.4 \times$ 0.2 meters adopts the box-shaped arch structure. The wall thickness of the steel plate is $25 \mathrm{~mm}$, and the lower prestressed rods adopt two $750 \mathrm{MPa}$ high-strength prestressed steel rods with a diameter of 0.10 meters.

The distance between vertical wire slings is 40 meters. The steel wire sling adopts $1860 \mathrm{MPa}$ high-strength steel wire rope, and the diameter of the steel wire sling is $0.12 \mathrm{~m}$.

The curved steel beam is provided with diagonal carbon fiber suspension slings connected to the stiffening beam at a distance of 120 meters. The diagonal carbon fiber suspension slings adopt the $4000 \mathrm{MPa}$ high-strength carbon fiber cable with a diameter of 0.12 meters.

The stiffening beam structure adopts a three-box streamlined steel box beam similar to the Messina Strait Bridge. The width of the stiffening beam is 60 meters, and the height of the stiffening beam is 15 meters.

The central area of the suspension bridge is provided with a concrete-filled steel tube arch central buckle to improve the integrity of the bridge and reduce the longitudinal displacement of the stiffening beam. The span of the arched central buckle is 150 meters and the height is 30 meters.

In this paper, ANSYS software was used to analyze the hyperbolic parabolic mixed space cable suspension bridge. A $5000 \mathrm{~m}$ parallel cable suspension bridge model was established as a reference for comparative analysis.

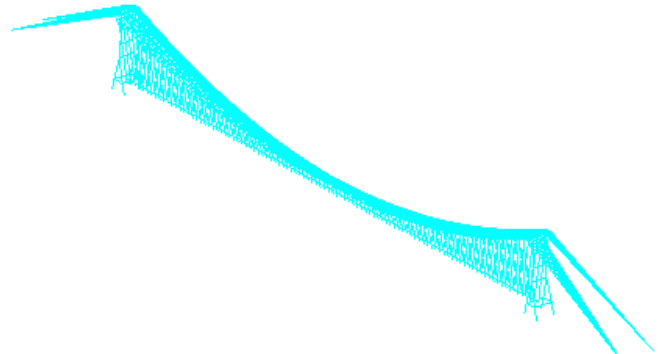

Figure 3. Hyperbolic paraboloid mixed space cable suspension bridge model

\section{Dynamic modal analysis}

The cable system of the space cable suspension bridge is complex, and it is difficult to find the shape automatically through the software. For the hyperbolic parabolic mixed space cable suspension bridge in this paper, MIDAS software was used to iteratively iterate to determine the bridge shape and cable initial stress. Then ANSYS was used for subsequent dynamic analysis. Fig.4 and Fig.5 show the representative vibration modes of the parallel suspension bridge and the hyperbolic parabolic mixedspace suspension bridge respectively. Table1 and Table2 show the vibration frequencies and modes of the two bridges.

Table1. Natural frequency and vibration mode of parallel cable suspension bridge

\begin{tabular}{|c|c|c|}
\hline order & $\begin{array}{l}\text { frequency } \\
(\mathrm{Hz})\end{array}$ & Mode shape \\
\hline 1 & 0.023082 & $\begin{array}{l}\text { first-order positive symmetric lateral } \\
\text { bending }\end{array}$ \\
\hline 2 & 0.036529 & longitudinal drift \\
\hline 3 & 0.038249 & $\begin{array}{c}\text { first-order antisymmetric lateral } \\
\text { bending }\end{array}$ \\
\hline 4 & 0.051164 & $\begin{array}{c}\text { first-order antisymmetric vertical } \\
\text { bending }\end{array}$ \\
\hline 5 & 0.057903 & lateral vibration of main cables \\
\hline 6 & 0.058462 & positive symmetric lateral bending \\
\hline 7 & 0.065518 & $\begin{array}{l}\text { first-order positive symmetric } \\
\text { vertical bending }\end{array}$ \\
\hline 8 & 0.072958 & positive symmetric lateral bending \\
\hline 9 & 0.078812 & lateral vibration of main cables \\
\hline 10 & 0.079882 & first order positive symmetric torsion \\
\hline 11 & 0.080597 & antisymmetric lateral bending \\
\hline 12 & 0.088853 & positive symmetric vertical bending \\
\hline 13 & 0.097143 & antisymmetric vertical bending \\
\hline 14 & 0.098884 & first order antisymmetric torsion \\
\hline
\end{tabular}

Remarks: Parallel cable suspension bridge adopts traditional gate tower.

flexible central buckle for parallel cable suspension bridge.

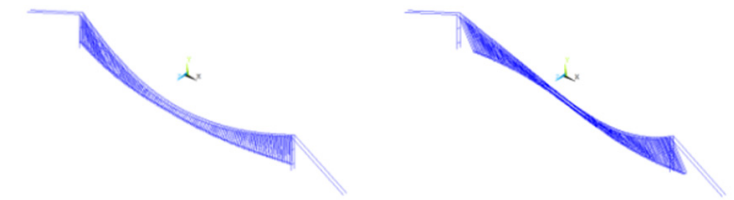

(1) 1 st mode $(0.02308 \mathrm{~Hz})$ (2) 2 nd mode $(0.03653 \mathrm{~Hz})$

(Positive symmetrical lateral bending) (Antisymmetric lateral bending)

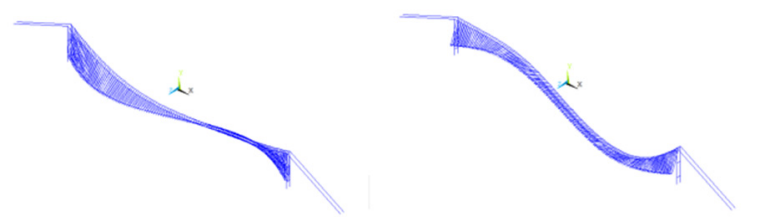

(3) 3rd mode $(0.03825 \mathrm{~Hz})$ (4) 4 th mode $(0.05116 \mathrm{~Hz})$

(Antisymmetric lateral bending) (Antisymmetric vertical bending)

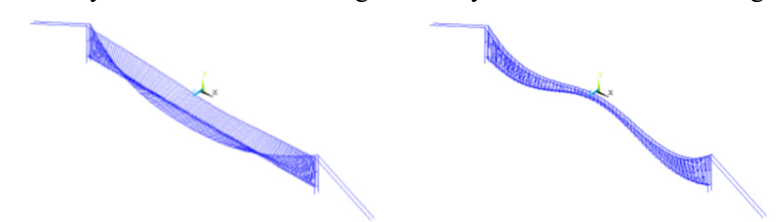

(5) 5th mode $(0.05790 \mathrm{~Hz})(6) 7$ th mode $(0.05846 \mathrm{~Hz})$ (Lateral vibration) (Positive symmetric vertical bending)

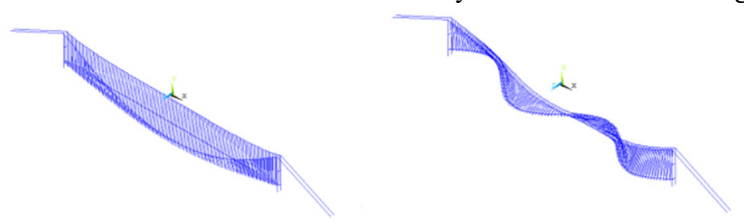

(7) 10th mode $(0.07988 \mathrm{~Hz})(8) 14$ th mode $(0.09888 \mathrm{~Hz})$ (Positive symmetric torsion) (Antisymmetric torsion)

Figure 4. Representative vibration mode diagrams of parallel cable suspension bridge 
Table2. Natural frequency and vibration mode of hyperbolic paraboloid mixed space suspension bridge

\begin{tabular}{|c|c|c|}
\hline order & $\begin{array}{l}\text { frequency } \\
(\mathrm{Hz})\end{array}$ & mode shape \\
\hline 1 & & first-order positive symmetric \\
\hline 1 & 0.02786 & lateral bending \\
\hline 2 & 0.05487 & $\begin{array}{c}\text { first-order antisymmetric lateral } \\
\text { bending }\end{array}$ \\
\hline 3 & 0.06769 & $\begin{array}{c}\text { first-order antisymmetric vertical } \\
\text { bending }\end{array}$ \\
\hline 4 & 0.06912 & $\begin{array}{l}\text { first-order positive symmetric } \\
\text { vertical bending }\end{array}$ \\
\hline 5 & 0.07170 & positive symmetric lateral bending \\
\hline 6 & 0.07564 & bending \\
\hline 7 & 0.08017 & antisymmetric lateral bending \\
\hline 8 & 0.08559 & $\begin{array}{c}\text { positive symmetric vertical } \\
\text { bending }\end{array}$ \\
\hline 9 & 0.08560 & antisymmetric lateral bending \\
\hline 10 & 0.08846 & antisymmetric vertical bending \\
\hline 11 & 0.09374 & antisymmetric vertical bending \\
\hline 12 & 0.09838 & positive symmetric lateral bending \\
\hline 13 & 0.10340 & positive symmetric lateral bending \\
\hline 14 & 0.10660 & $\begin{array}{l}\text { positive symmetric vertical } \\
\text { bending }\end{array}$ \\
\hline 15 & 0.10828 & antisymmetric vertical bending \\
\hline 16 & 0.12434 & antisymmetric vertical bending \\
\hline 17 & 0.13448 & antisymmetric lateral bending \\
\hline 18 & 0.14573 & antisymmetric lateral bending \\
\hline 19 & 0.15824 & antisymmetric vertical bending \\
\hline 22 & 0.18214 & $\begin{array}{l}\text { first-order positive symmetric } \\
\text { torsion }\end{array}$ \\
\hline 29 & 0.25577 & first-order antisymmetric torsion \\
\hline
\end{tabular}

Remarks: the space mixed cable suspension bridge adopts herringbone limb bridge tower.

Spatial mixed cable suspension bridge is provided with arched central buckle.

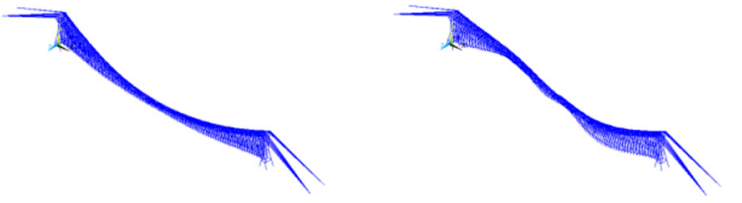

(1) 1 st mode $(0.02786 \mathrm{~Hz})$ (2) 2nd mode $(0.05487 \mathrm{~Hz})$ (Positive symmetrical lateral bending) (Antisymmetric lateral bending)
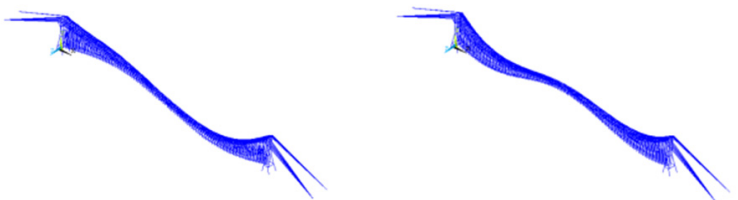

(3) 3rd mode $(0.06769 \mathrm{~Hz})$ (4) 4 th mode $(0.06912 \mathrm{~Hz})$ (antisymmetric vertical bending) (positive symmetric vertical bending)

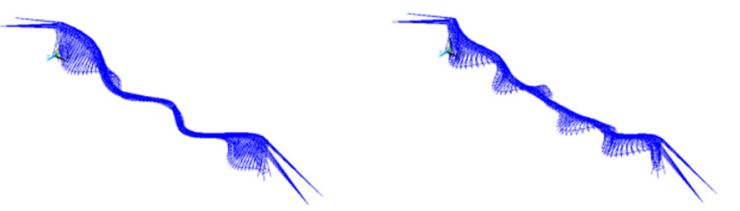

(5) 22nd mode $(0.18214 \mathrm{~Hz})$ (6) 29 th mode $(0.25577 \mathrm{~Hz})$ (Positive symmetric torsion) (Antisymmetric torsion)

Figure 5. Representative vibration mode diagrams of a hyperbolic parabolic mixed space suspension bridge
The above calculation results show that:

The first few vibration modes of the hyperbolic parabolic mixed space cable suspension bridge and the parallel cable suspension bridge are basically similar, and there are obvious vibration mode groupings. However, the space mixed cable suspension bridge adopts herringbone four-limbs bridge tower and is provided with an archshaped central buckle, which improves the longitudinal rigidity of the suspension bridge and avoids the longitudinal drift vibration mode.

The torsional modes of the parallel suspension bridge appear in the 10th and 14th orders, and the corresponding frequencies are $0.079882 \mathrm{~Hz}$ (first-order positive symmetry) and $0.098884 \mathrm{~Hz}$ (first-order antisymmetric). The torsional vibration modes of the hyperbolic parabolic mixed space suspension bridge appear at the 22nd and 29th orders respectively, with corresponding frequencies of $0.18214 \mathrm{~Hz}$ (first-order positive symmetry) and 0.25577 $\mathrm{Hz}$ (first-order antisymmetric).

The torsion-bending frequency ratios of the hyperbolic parabolic mixed space cable suspension bridge and the parallel suspension bridge are: hyperbolic parabolic space suspension bridge 2.69, parallel suspension bridge 1.56 . Therefore, the hyperbolic parabolic mixed space cable suspension bridge has good torsion resistance.

\section{Stability analysis of flutter}

Flutter is a phenomenon of divergent instability of the structure under wind load. In this paper, the Selberg formula [11] was used to analyze the flutter stability of the suspension bridge.

$$
\begin{gathered}
V_{c r}=\eta_{s} \eta_{\alpha} \omega_{t} b_{1} \sqrt{\frac{r}{b_{1}} \mu\left[1-\left(\frac{\omega_{v}}{\omega_{t}}\right)^{2}\right]} \\
\mu=M / \pi \rho b_{1}{ }^{2}
\end{gathered}
$$

In the formula:

$\eta_{s}$ is the influence factor of the cross-sectional shape of the main beam.

$\eta_{\alpha}$ is the angle-of-attack effect coefficient . For a flat plate section at $0^{\circ}$ wind angle of attack, $\eta_{s}$ and $\eta_{\alpha}$ both take 1.0 .

$r$ is the inertia radius of the bridge section (including stiffening beam and main cable).

$b_{1}$ is the half-bridge width of the stiffening beam section.

$\mu$ is the density ratio of bridge to air.

$m$ is the mass density of stiffening beam and main cable.

$\omega_{t}$ and $\omega_{v}$ are the lowest order torsional circle frequency and the vertical circle frequency respectively.

Definition:

$V_{c r}^{m}, V_{c r}^{p}$ —critical flutter wind speed of hyperbolic parabolic suspension bridge and parallel suspension bridge.

$\omega_{t}^{m} 、 \omega_{v}^{m}, \omega_{t}^{p} 、 \omega_{v}^{p}$ - the lowest order torsional circle frequency and vertical bending circle frequency of the hyperbolic parabolic suspension bridge and parallel suspension bridge. 
From Equation 3, the calculation results of the ratio of the flutter critical wind speed of the two suspension bridges are as follows:

(1) In the parallel cable suspension bridge scheme, $M=68440 \mathrm{~kg} / \mathrm{m}, \quad \omega_{t}^{P}=0.5019 \mathrm{rad} / \mathrm{s}, \omega_{v}^{P}=0.3215 \mathrm{rad} / \mathrm{s}$. After calculating $I=2.34 \times 10^{3} \mathrm{~m}^{4}, r=18.55 \mathrm{~m}, \mu=$ 19.76, therefore, the critical flutter wind speed $V_{c r}^{P}$ of the parallel cable suspension bridge is:

$V_{c r}^{P}=0.8 \times 0.8 \times 0.5019 \times 30 \times \sqrt{\frac{18.55}{30} \times 19.79 \times\left[1-\left(\frac{0.3215}{0.5019}\right)^{2}\right]}$

$=25.87 \mathrm{~m} / \mathrm{s}$

(2) In the spatial hybrid cable suspension bridge scheme, $\quad \mathrm{M}=69360 \mathrm{~kg} / \mathrm{m}, \quad \omega_{t}^{m}=1.144 \mathrm{rad} / \mathrm{s}, \quad \omega_{v}^{m}=$ $0.4253 \mathrm{rad} / \mathrm{s}, I=2.34 \times 10^{3} \mathrm{~m}^{4}, \quad r=18.55 \mathrm{~m}, \mu=$ 20.03, therefore, the spatial hybrid cable The critical flutter wind speed $V_{c r}^{m}$ of the suspension bridge is:

$$
\begin{aligned}
V_{c r}^{m} & =0.8 \times 0.8 \times 1.144 \times 30 \times \sqrt{\frac{18.55}{30} \times 20.03 \times\left[1-\left(\frac{0.4253}{1.144}\right)^{2}\right]} \\
& =71.78 \mathrm{~m} / \mathrm{s}
\end{aligned}
$$

$V_{c r}^{m}=71.78 \mathrm{~m} / \mathrm{s}, V_{c r}^{p}=25.87 \mathrm{~m} / \mathrm{s}$. The critical flutter wind speed of the hyperbolic parabolic space hybrid cable system suspension bridge has been greatly improved, with an increase of $177 \%$.

\section{Temporary auxiliary anti-wind cable}

At present, earthquakes cannot be predicted, but super strong typhoons can be accurately predicted. The threelevel fortification principle of seismic design of structures are: no damage under small earthquakes, repairable under middle earthquakes, and no downfall in large earthquakes. It is recommended that the wind-resistant design of the super-long-span suspension bridge adopts the two-level fortification principle: no damage under the middle wind, and a temporary wind-resistant cable should be set under the strong wind.

The 5,000-meter hyperbolic parabolic spatial mixed cable-net suspension bridge in this paper can withstand the strong typhoon of level 18. However, the current global El Niño phenomenon is intensifying, and the intensity of typhoons is increasing. The design reference period of the ultra-long-span suspension bridge is 100 years. Therefore, it is necessary to make psychological preparations for encountering strong typhoons above 19.

This paper draws on the principle of ship anchor cable and puts forward the technical measures for emergency filing of temporary auxiliary wind-resistant cable. The use requirements of the 5,000-meter hyperbolic parabolic mixed space cable super-long-span suspension bridge are as follows:

1. In case of 8-12 level typhoon, the channel is not blocked and the bridge is used normally;

2. In case of 13-18 level typhoon, the channel is blocked and suspending bridge deck traffic;

3. In case of typhoon level 19 or above, activating temporary auxiliary wind resistant cables.

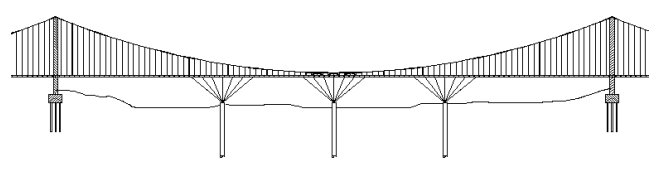

Figure 6. Temporary wind resistance cable

The construction method of temporary wind-resistant cable is as follows: ground anchor cable pile shall be constructed first. The top of the pile is connected with temporary carbon fiber wind-resistant cables. The carbon fiber wind-resistant cables are "deeply buried" in the seabed trench (the thin line is pulled to the bridge tower), which does not affect the channel operation.

When encountering strong typhoon weather, quickly pull the carbon fiber wind-resistant cable to the mid-span stiffener beam deck and fix it firmly on the stiffener beam deck to ensure that there is no slight structural damage to the super-large-span bridge. After the typhoon disaster, the wind-resistant cable will be pulled back to the original deep groove of the seabed to resume traffic.

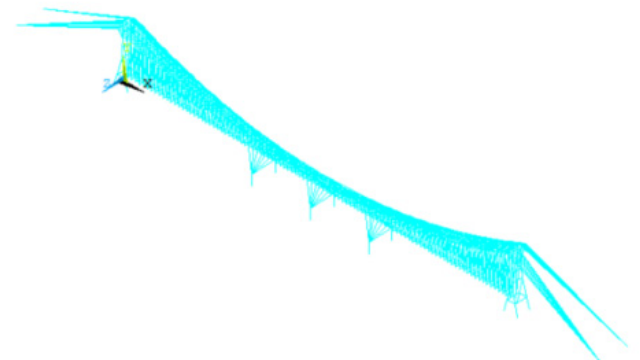

Figure 7. Model of hyperbolic parabolic mixed space cable suspension bridge with additional wind resistant cables

In this design, three ground anchor cable piles are set on each side of the 5000-meter-level strait suspension bridge. The diameter of the ground anchor cable pile is 4 meters, and the length of the ground anchor cable pile is 180 meters. The ground anchor cable pile has a longitudinal spacing of 600 meters and a horizontal spacing of 120 meters. The angle between the wind resistant cable and the vertical coordinate axis of the stiffening beam is about $30^{\circ}$. Each ground anchor cable pile is equipped with 7 carbon fiber wind resistant cables with a diameter of 0.5 meter which are connected with the stiffening beam to provide vertical and lateral restraint for the stiffening beam.

\subsection{Dynamic modal analysis}

In this paper, ANSYS software was used for finite element analysis, and the representative vibration modes of the hyperbolic parabolic mixed space cable suspension bridge with temporary wind-resistant cables can be obtained as shown in Figure 8.

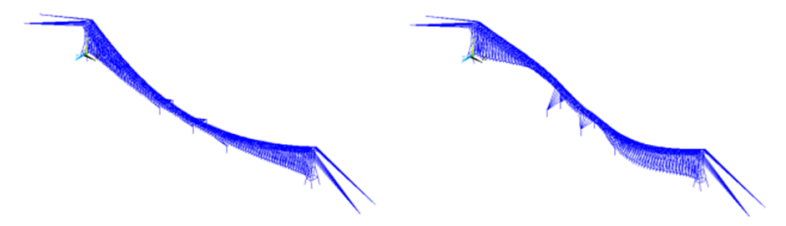

(1) 1 st mode $(0.02951 \mathrm{~Hz})(2) 2$ nd mode $(0.05953 \mathrm{~Hz})$ (Positive symmetrical lateral bending) (Antisymmetric lateral bending) 


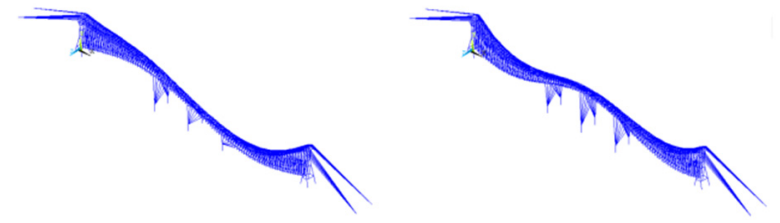

(3) 3ed mode $(0.07228 \mathrm{~Hz})$ (4) 4th mode $(0.07347 \mathrm{~Hz})$ (Antisymmetric vertical bending) (Positive symmetrical vertical bending)

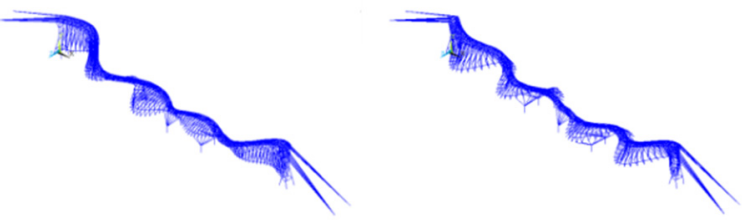

(5) 27 th mode $(0.23829 \mathrm{~Hz})$ (6) 30th mode

$(0.29728 \mathrm{~Hz})$

(Positive symmetric torsion) (Antisymmetric torsion)

Figure 8. Vibration mode of hyperbolic parabolic mixed space suspension bridge with temporary wind resistant cables

\subsection{Analysis of critical wind speed of flutter}

Through calculation, the following calculation parameters of the hyperbolic parabolic space hybrid cable suspension bridge can be obtained: $\eta_{s}$ and $\eta_{\alpha}$ are both 0.8 , and the calculation results of the flutter critical wind speed are as follows: After setting the temporary wind resistance cable, in the calculation, the temporary wind resistance cable should be considered. The vertical force component is equivalent to $M=81540 \mathrm{~kg} / \mathrm{m}$ $I=2.34 \times 10^{3} \mathrm{~m}^{4}, r=18.55 \mathrm{~m}, \mu=23.54, \omega_{\mathrm{t}}^{\mathrm{L}}=1.4972 \mathrm{rad} / \mathrm{s}$, $\omega_{v}^{L}=0.4542 \mathrm{rad} / \mathrm{s}$.

Therefore, after the temporary windresistant cable is installed, the critical flutter wind speed $V_{c r}^{L}$ of a 5000meter spatial hybrid cable suspension bridge is:

$$
\begin{aligned}
V_{c r}^{L} & =0.8 \times 0.8 \times 1.4972 \times 30 \times \sqrt{\frac{18.55}{30} \times 23.54 \times\left[1-\left(\frac{0.4542}{1.4972}\right)^{2}\right]} \\
& =104.5 \mathrm{~m} / \mathrm{s}
\end{aligned}
$$

\subsection{Comparative analysis}

Table3. Comparison before and after installing temporary

\begin{tabular}{|c|c|c|}
\hline Comparison parameters & $\begin{array}{c}\text { Hyperbolic } \\
\text { parabolic } \\
\text { suspension bridge }\end{array}$ & $\begin{array}{l}\text { Hyperbolic parabolic } \\
\text { suspension bridge with } \\
\text { temporary wind- } \\
\text { resistant cables }\end{array}$ \\
\hline $\begin{array}{l}\text { First-order lateral } \\
\text { bending frequency } \\
(\mathrm{Hz})\end{array}$ & 0.02786 & 0.02951 \\
\hline $\begin{array}{l}\text { First-order vertical } \\
\text { bending frequency } \\
\qquad(\mathrm{Hz})\end{array}$ & 0.06912 & 0.07347 \\
\hline $\begin{array}{l}\text { First-order positive } \\
\text { symmetric torsion } \\
\text { frequency }(\mathrm{Hz})\end{array}$ & $\begin{array}{c}0.18214 \\
(22 \mathrm{nd} \text { order })\end{array}$ & $\begin{array}{c}0.23829 \\
(27 \text { th order })\end{array}$ \\
\hline $\begin{array}{c}\text { First-order } \\
\text { antisymmetric torsion } \\
\text { frequency }(\mathrm{Hz})\end{array}$ & $\begin{array}{c}0.25577 \\
\text { (29th order) }\end{array}$ & $\begin{array}{c}0.29728 \\
(30 \text { th order) }\end{array}$ \\
\hline Torsion ratio & 2.69 & 3.30 \\
\hline $\begin{array}{l}\text { Flutter critical wind } \\
\text { speed }(\mathrm{m} / \mathrm{s})\end{array}$ & 71.78 & 104.5 \\
\hline
\end{tabular}
wind resistant cable for hyperbolic paraboloid suspension
The modal characteristics and critical wind speed of the hyperbolic parabolic mixed space cable suspension bridge before and after the installation of wind resistant cables are shown in Table 3.

The analysis shows that the provision of temporary auxiliary anti-wind cables can significantly increase the torsional frequency and torsional bending frequency ratio. The 27th order mode of the hyperbolic parabolic mixed space suspension bridge with temporary wind-resistant cables is a positively symmetric torsional mode with a frequency of $0.23829 \mathrm{~Hz}$. The 30th order mode is an antisymmetric torsional mode with a frequency of $0.29728 \mathrm{HZ}$. The ratio of torsion frequency is as high as 3.30, which is $22.7 \%$ higher than that of the model without wind resistance cable. It can be seen that the provision of temporary auxiliary wind-resistant cables can significantly improve the wind-resistant stability of the suspension bridge.

The 5000-meter hyperbolic parabolic mixed space cable suspension bridge without a wind-resistant cable has a critical wind speed value of $71.78 \mathrm{~m} / \mathrm{s}$, which can resist a strong typhoon of level 18. After the temporary auxiliary wind-resistant cable is activated, the critical wind speed of flutter can reach $104.5 \mathrm{~m} / \mathrm{s}$, which can meet the requirements of resisting the 18th-level rare super strong typhoon. Therefore, the problem of wind resistance stability of the 5,000-meter super-long-span suspension bridge has been fundamentally solved, marking that mankind has the scientific and technological capability to build a 5,000-meter strait suspension bridge.

\section{Conclusion}

(1) The torsional modes of the parallel suspension bridge appear at the 10th and 14th orders, and the corresponding frequencies are $0.079882 \mathrm{~Hz}$ (first-order positive symmetry) and $0.098884 \mathrm{~Hz}$ (first-order antisymmetric). The torsional modes of the hyperbolic parabolic mixedspace suspension bridge appear in the 22nd and 29th modes respectively with corresponding frequencies of $0.18214 \mathrm{~Hz}$ (first-order positive symmetry) and $0.25577 \mathrm{~Hz}$ (first-order antisymmetric).The hyperbolic parabolic mixed space cable suspension bridge has good torsion resistance performance.

(2) In this paper, the dynamic modal comparison analysis of hyperbolic parabolic mixed space cable suspension bridge and parallel suspension bridge was carried out. The analysis shows that the torsion-bending frequency ratio of hyperbolic parabolic space suspension bridge is 2.69 and that of parallel suspension bridge is 1.56 . The critical wind speed for flutter of hyperbolic parabolic space suspension bridge is $71.78 \mathrm{~m} / \mathrm{s}$ and that of parallel suspension bridge is $25.87 \mathrm{~m} / \mathrm{s}$. The former has increased by $117 \%$ compared to the latter. Therefore, the hyperbolic parabolic mixed space cable suspension bridge space suspension bridge has good wind stability.

(3) In order to resist the rare super strong typhoon, technical measures to add temporary auxiliary anti-wind cables were proposed. After the temporary auxiliary windresistant cable is activated, the torsional frequency does not appear until the 27th mode (positive symmetric 
torsional frequency is $0.23829 \mathrm{~Hz}$ ), and the ratio of torsion-bending frequency is as high as 3.30. The flutter critical wind speed value reaches $104.5 \mathrm{~m} / \mathrm{s}$, which can resist the 18-level rare super strong typhoon and ensure the safety of the bridge.

(4) The technical solution of the hyperbolic parabolic mixed space cable suspension bridge structure can fundamentally solve the wind stability problem of the 5,000-meter super-long-strait suspension bridge, which indicates that mankind has the scientific and technological capability to build a 5,000-meter-level strait suspension bridge.

\section{References}

1. Xiang Haifan Ge Yaojun. On aerodynamic limits to suspension bridges[J]. China civil engineering journal,2005,38(01):60-70.(In Chinese)

2. Tang M-C. Super-long span bridges[J]. Structure \& Infrastructure Engineering: Maintenance, Management, Life Cycle Design \& Performance,2017,13(6):722-730.

3. Sato H, Hirahara N, Fumoto K, Hirano S. Full aeroelastic model test of a super long-span bridge with slotted box girder[J].Journal of Wind Engineering \& Industrial Aerodynamics,2002,90(12):2023-2032.

4. Chen ze. Conceptual design and wind resistance research of the $5000 \mathrm{~m}$-span suspension bridge with CFRP cables[D]. Southwest jiaotong university,2016.(In Chinese)

5. Vu T-V, Kim Y-M, Lee H-E. Coupled flutter analysis of long-span bridges using full set of flutter derivatives[J]. KSCE Journal of Civil Engineering,2016, 20(4):1501-1513.

6. Zhang Xinjun. Study of the wind stability of longspan suspension bridges with spatial cable systems[J]. China civil engineering journal,2011,44(06):8086.(In Chinese)

7. Tang, H., Li, Y., \& Shum, K. M.. Flutter performance of long-span suspension bridges under non-uniform inflow[J]. Advances In Structural Engineering, 2018, 21(2): 201-213.

8. Abbas T, Kavrakov I, Morgenthal G. Methods for flutter stability analysis of long-span bridges: a review[J]. Bridge Engineering, 2017,170(4):271-310. 